\title{
SISTEM INFORMASI MONITORING PERANGKAT DAN LINK GPON DUAL HOMING NODE B DI PT.XYZ
}

\author{
Ari Sujarwo ${ }^{1)}$, Muhammad Wijdan Fauzi ${ }^{2)}$ \\ Jurusan Teknik Informatika, Fakultas Teknologi Industri, Universitas Islam Indonesia, ${ }^{1,2)}$ \\ Jl.Kaliurang Km.14,5, Sleman, Yogyakarta \\ Email : ari.sujarwo@uii.ac.id ${ }^{1)}$,wijdan135@gmail.com ${ }^{2)}$
}

\begin{abstract}
ABSTRAK
Dual Homing ONT mechanism implemented by PT. XYZ to establish Node B BTS network. This mechanism has reliability benefit due to dual uplinks support it has, so when one of the dual uplinks goes down, the backup link will then getting active and forwarding data.

At this time, current market available monitoring system unable to detect failure on both uplinks when one of them inactive due to system failure. This problem occurs because device probing could only be established up to ONT. In this case, engineer does not aware whether their link is up or not, and dual homing scheme does not really works.

Due to problem which is explained above, this paper offers a new approach to monitor two target of each ONT: the IP address and the logical port of the OLT where the ONT connected.

In this mechanism, if one of the link fail, system will send an alert to engineer based on the status of the logical port to repair the broken link.
\end{abstract}

Keywords : Dual Homing, ONT GPON, Monitoring.

\section{PENDAHULUAN}

PT. XYZ bergerak di bidang penyedia layanan seluler bergerak dengan teknologi Global System for Mobile communication (GSM), yaitu sebuah teknologi seluler digital yang digunakan untuk mentransmisikan suara dan data. PT. XYZ mulai menyediakan layanan mobile data pada tahun 2002 dengan teknologi General Packet Radio Service (GPRS) yang dapat mentransmisikan data dengan bandwidth atau lebar pita sebasar 40 Kilobit per second (Kbps), kemudian berkembang dengan Enhanced Data rates for GSM Evolution (EDGE) pada tahun 2004 dengan bandwidth hingga tiga kali lebih besar daripada teknologi GPRS. Perkembangan selanjutnya adalah thirdgeneration mobile service yang lebih dikenal dengan $3 \mathrm{G}$ pada tahun 2006, dan pada tahun 2015 pengguna dapat menikmati layanan data berkecepatan tinggi dengan teknologi High Speed Packet Access Plus (HSPA+) yang secara teori dapat menyediakan bandwidth sebesar 42 Megabit per second(Mbps) (GSMA, "GSM.” 2015).
Pengguna dapat menikmati layanan GSM dengan memanfaatkan keberadaan sebuah Base Tranceiver Station (BTS). BTS adalah sebuah network element di dalam jaringan seluler yang berfungsi sebagai penghubung antara User Equipment (UE) dengan Mobile Switching Center (MSC) yang berperan sebagai pengendali hubungan pembicaraan. BTS memancarkan sinyal yang dapat diterima oleh UE. Perangkat BTS dipasang pada sebuah menara atau gedung yang tinggi agar dapat menjangkau pengguna pada jangkauan area yang luas. Sebuah BTS yang dapat melayani teknologi $3 \mathrm{G}$ atau yang lebih baru disebut dengan BTS Node - B. Dalam topologi jaringan 3G, BTS Node-B terhubung dengan Radio Network Controller (RNC) dan Serving GPRS Support Node (SGSN) yang menyediakan koneksi ke internet. (J. A. De Vriendt).

BTS Node - $B$ menyediakan layanan berkecepatan tinggi untuk pengguna, oleh karena itu media transmisi yang digunakan untuk menghubungkan BTS Node - $B$ dengan RNC juga mempunyai kapabilitas mentransmisikan data dengan kecepatan tinggi pula. PT. XYZ menggunakan media 
transmisi kabel Fiber Optic (FO), yaitu kabel yang berisi serat kaca sangat kecil untuk menghantarkan cahaya yang mentransmisikan data.

Pengelolaan interkoneksi antara BTS Node - B memanfaatkan teknologi Gigabitcapable Passive Optical Network (GPON). GPON merupakan teknologi jaringan akses menggunakan media kabel serat optik untuk melayani pelanggan perumahan maupun bisnis. Teknologi ini memiliki kapabilitas bandwidth yang besar, yaitu 2,4 Gigabit per second (Gbps) untuk downstream dan $1,2 \mathrm{Gbps}$ untuk upstream. "nominal line rates of $2.4 \mathrm{Gbit} / \mathrm{s}$ in the downstream direction and $1.2 \mathrm{Gbit} / \mathrm{s}$ and $2.4 \mathrm{Gbit} / \mathrm{s}$ in the upstream direction” (Itu-T, “G.984).

Jaringan GPON memiliki dua perangkat aktif yaitu Optical Line Terminal (OLT) yang berada di sisi penyedia layanan dan Optical Network Terminal (ONT) yang ditempatkan di sisi pelanggan. Reliabilitas layanan 3G dapat ditingkatkan dengan diterapkannya mekanisme dual - homing. Mekanisme ini memungkinkan sebuah ONT yang mencatu layanan BTS Node - B terhubung ke dalam dua OLT yang berbeda dengan jalur atau link FO yang berbeda pula. Hal ini dimaksudkan agar pada saat salah satu kabel FO yang menghubungkan ONT BTS Node - $B$ terputus, masih ada satu jalur cadangan yang dapat digunakan sehingga layanan data $3 \mathrm{G}$ di BTS tersebut masih dapat berjalan.

Sebagai mekanisme pengawasan terhadap perangkat-perangkat jaringan, digunakan beberapa perangkat lunak monitoring antara lain :

1. U31 Network Management System (NMS) yaitu perangkat lunak yang dibuat oleh vendor ZTE. Perangkat lunak berbasis Desktop Client ini bersifat close source karena dibuat oleh vendor ZTE dan hanya bisa digunakan untuk memonitor perangkat dengan manufaktur yang sama.

2. Cacti yaitu sebuah perangkat lunak berbasis web yang dapat melakukan monitoring perangkat jaringan yang berbasis Internet Protocol (IP). Cacti dapat memonitor perangkat jaringan dengan menggunakan protokol Internet Control Message Protocol (ICMP) Ping yaitu protokol yang dapat digunakan untuk mengetahui apakah sebuah perangkat jaringan dalam kondisi hidup atau mati.

Kemudian Cacti menampilkan hasilnya dan memberikan peringatan kepada pengguna apabila perangkat yang dimonitor mengalami kegagalan pada saat pengecekan yang mengindikasikan perangkat tersebut terganggu (S. Maruyama, K. Tanahashi, and T. Higuchi). Cacti dimanfaatkan untuk mengawasi perangkat jaringan, termasuk perangkat GPON baik di sisi OLT maupun ONT terutama perangkat GPON yang digunakan untuk melayani BTS Node $-B$.

\section{RUMUSAN MASALAH}

Berdasarkan pendahuluan di atas, maka disusun suatu rumusan masalah yaitu bagaimana memonitor dua jalur kabel Fiber Optic yang digunakan untuk perangkat ONT Dual Homing.

\section{KAJIAN PUSTAKA}

\subsection{Sistem Informasi Monitoring}

Sistem informasi monitoring adalah sebuah sistem yang membantu seseorang untuk mengetahui kondisi dari suatu hal. Misalnya seorang petugas keamanan yang ditugaskan untuk mengawasi sebuah kompleks perkantoran yang dilengkapi dengan sejumlah kamera pengawas yang hasilnya ditampilkan ke dalam layar monitor. Keberadaan kamera tersebut adalah sebagai sensor agar para petugas keamanan dapat mengawasi tempat tertentu dengan mudah tanpa harus mendatanginya.

Pada bidang jaringan komputer, sistem informasi monitoring dibangun dengan tujuan yang sama, yaitu menjadikan seseorang sebagai administrator yang baik. "Good system administrators recognize problems long before anyone asks, "Hey, is the Internet down? " (W. Barth).

Seorang pengelola jaringan memiliki tugas untuk mengawasi kondisi dari sebuah jaringan agar tetap dalam kondisi yang baik, 
sehingga pengguna dapat terlayani dengan baik. Sistem informasi monitoring jaringan memungkinkan sang administrator untuk mengetahui lebih dini jika terjadi gangguan pada jaringan yang dikelolanya.

Salah satu cara untuk memonitor kondisi jaringan adalah dengan memanfaatkan protokolinternet Control Message Protocol (ICMP) danSimple Network Management Protocol (SNMP).

\subsection{Simple Network Management Protocol}

SNMP dapat digunakan untuk mengumpulkan informasi kondisi sebuah perangkat jaringan dengan hasil yang lebih beragam dibandingkan dengan ICMP. Sebagai contoh, SNMP dapat digunakan untuk memonitor besaran lalu lintas datapada sebuah router. SNMP juga dapat digunakan untuk memonitor beban CPU pada sebuah perangkat jaringan. Protokol SNMP digunakan bersama - sama dengan sebuah Network Management System (NMS) untuk mengumpulkan data dari perangkatperangkat yang diawasinya, sedang ICMP hanya sebatas memonitor dengan kesimpulan sebuah perangkat hidup atau mati saja.

"The Simple Network Management Protocol (SNMP) is an Internet-standard protocol for managing hosts on an IP network" (D. R. Mauro and K. J. Schmidt ). Sistem yang ingin memanfaatkan SNMP untuk mendapatkan data dari perangkat jaringan harus memiliki sebuah database yang berisi Object Identifier (OID) yang digunakan protokol SNMP untuk berkomunikasi. Database ini disebut dengan Management Information Base (MIB)

"The MIB is a database containing Object Identifier (OID) information" (P. Murray).

Namun umumnya pihak vendor perangkat menyatakan MIB yang digunakan untuk pengambilan data yang spesifik yang mereka gunakan untuk berkomunikasi antara NMS dengan perangkatnya bersifat proprietary atau tertutup karena merupakan hak milik dari vendor tersebut. Akan tetapi MIB standard juga masih tersedia untuk pengambilan informasi dasar seperti system uptime atau system name. Oleh karena itu, pihak vendor menyediakan antar muka alternatif untuk memonitor perangkat yaitu melalui NMS dengan mekanisme Transaction Language 1 atau TL1.

\subsection{Transaction Language 1}

TL1 adalah sebuah mekanisme yang memungkinkan sebuah sistem yang ingin berkomunikasi dengan perangkat jaringan yang hanya berkomunikasi dengan bahasa proprietary. Hal ini dimungkinkan dengan keberadaan NMS sebagai perantara komunikasi proprietary yang berbeda tiaptiap vendor dengan sistem lain yang ingin berkomunikasi dengan perangkat. Gambar. 1 dibawah ini menerangkan skema konektivitas antara perangkat NMS dan sistem lain yang membutuhkan data dari perangkat. Sistem lain tersebut tidak secara langsung berkomunikasi dengan perangkat untuk mendapatkan data yang bersifat vendor proprietary, melainkan melalui perantara NMS.

"Transaction Language 1 (TL1) is a set of ASCII (American Standard Code for Information Interchange)-based instructions, or messages, that an operations support system (OSS) uses to manage a network element (NE) and its resources" (Cisco).

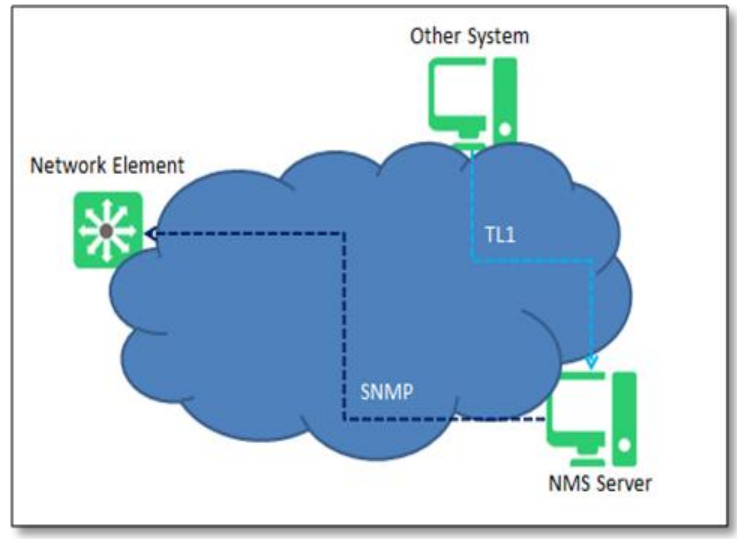

Gambar. 1 Skema Konektivitas Sistem Monitoring.

\subsection{Komuninasi Data Seluler}

Jaringan telepon seluler generasi pertama dibuat pada awal tahun 1980, dimana pada saat itu masing - masing negara 
mengembangkan sendiri sistem selulernya, yang berakibat pada keterbatasan penggunaan jaringan seluler hanya di negara tersebut. Barulah pada tahun 1982 sebuah kelompok bernama Groupe Special Mobile (GSM) untuk mengembangkan sistem seluler, kemudian pada tahun 1989 European Telecommunications Standards Institute (ETSI) membuat spesifikasi standard jaringan seluler dengan nama Global System for Mobile Communications (GSM). GSM merupakan generasi kedua sistem seluler yang mulai dikomersialisasi pada tahun 1991.

Komunikasi data pada generasi kedua (2G) sistem seluler ini menggunakan teknologi circuit - switched data (CSD) yang menawarkan lebar pita sebesar 14,4kbps. Kemudian hadir penerusnya yaitu High Speed CSD (HSCSD) dan General Packet Radio Service (GPRS) dengan lebar pita sebesar 57,6kbps, namun karena kekurangan yang dimiliki HSCSD yaitu penggunaan beberapa kanal radio sekaligus, operator lebih memilih untuk menggunakan teknologi GPRS yang dapat menutupi kekurangan HSCSD. Komunikasi data seluler generasi kedua berlanjut dengan teknologi penerus GPRS yaitu Enhanced Data Rate for Global Evolution (EDGE) pada tahun 2002.

Di jaringan GSM/GPRS, layanan suara maupun data dilayani dengan Base Station Subsystem (BSS) dan Network Subsystem (NSS). BSS terdiri dari Base Tranceiver Station (BTS) yang memancarkan sinyal radio untuk diterima telepon seluler, dan Base Station Controller (BSC) yang mengatur BTS dalam hal sumber daya dan handover yaitu perpindahan sebuah telepon seluler sedang berada di jangkauan BTS satu ke BTS lainnya. Sedangkan NSS dalam komunikasi suara atau telepon terdiri dari Mobile Switching Center (MSC), Visitor Location Register (VLR) dan Home Location Register (HLR). Untuk komunikasi data atau internet, di sisi NSS terdiri dari Serving GPRS Support Node (SGSN) dan Gateway GPRS Support Node
(GGSN).Jaringan GSM / GPRS dapat dilihat di Gambar. 2.

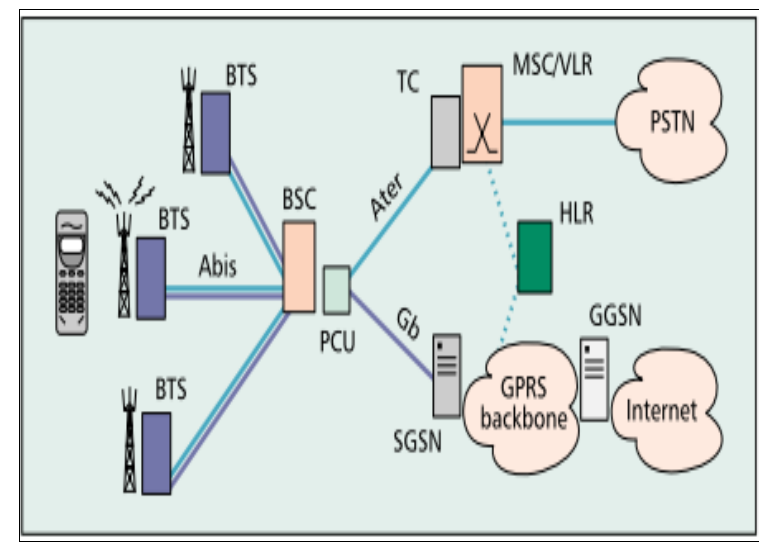

Gambar. 2 Jaringan GSM / GPRS.

Kebutuhan akan kecepatan yang lebih tinggi membuat International Telecommunication Union (ITU) membuat standard seluler generasi ketiga (3G) dengan nama Universal Mobile Telecommunications System (UMTS).

"The idea of $3 G$ became evident with the need for more capacity, new frequencies, and higher bit rates" (J. De Vriendt, P. Laine, C. Lerouge, and X. X. X. Xu).

Komunikasi data generasi ketiga diawali dengan High Speed Downlink Packet Aceess (HSDPA) yang menawarkan lebar pita hingga sebesar 384kbps. Jaringan 3G pertama dibangun pada tahun 2002 dan mulai digunakan pada tahun 2003. Jaringan 3G dilayani melalui Node $B$, yang setara dengan BTS, RadioNetwork Controller (RNC) yang setara dengan BSC, dan UMTS Core Network yang setara dengan NSS pada jaringan 2G.Jaringan UMTS dapat dilihat pada Gambar. 3.

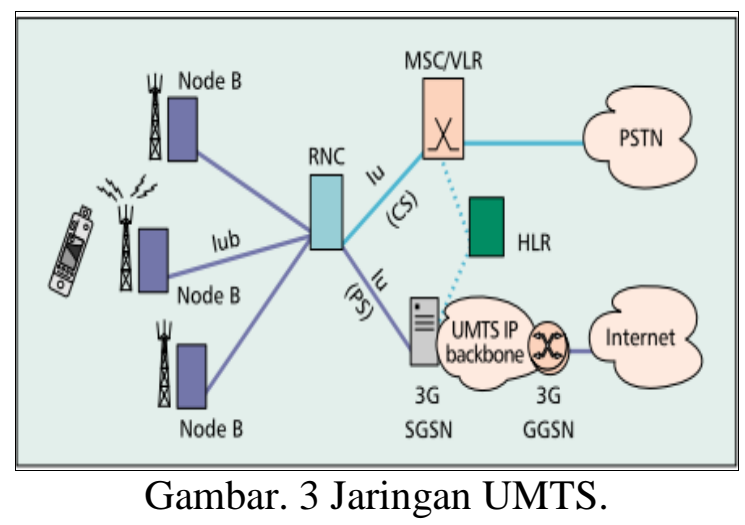


(J. De Vriendt, P. Laine, C. Lerouge, and X. X. X. Xu)

Node $B$ merupakan sebuah istilah yang merujuk pada sebuah BTS yang melayani layanan seluler 3G. Pada jaringan GSM 2G, koneksi antara BTS dengan BSC menggunakan gelombang radio, sedangkan pada jaringan $3 \mathrm{G}$, Node $B$ dengan RNC nya dihubungkan dengan media fisik misalnya kabel fiber optik karena membutuhkan bandwidth yang lebih besar.

\subsection{Passive Optical Network}

Fiber Optic atau serat optik adalah media transmisi data yang mampu mentransmisikan data dalam jumlah yang besar dan dalam waktu yang singkat, juga pada jarak yang jauh. Penerapan serat optik sebagai media transmisi data diawali dengan topologi point - to - point, dimana sebuah kabel yang secara khusus digunakan untuk menghubungkan Central Office (CO) menuju pelanggan. Pada Gambar. 4 (a) menunjukkan serat optik yang dibutuhkan untuk melayani sejumlah $\mathrm{N}$ pelanggan sejauh masing - masing $\mathrm{L} \mathrm{km}$ adalah sebanyak $\mathrm{N}$ kabel serat optik dengan panjang $\mathrm{L} \mathrm{km}$ dan sebanyak dengan $2 \mathrm{~N}$ konektor serat optik. Topologi ini yang paling sederhana namun memiliki cost atau biaya yang tinggi.

Untuk mengurangi banyaknya pemakaian serat optik, maka dibuat topologi curbswitched, yaitu dengan membangun $\mathrm{CO}$ di lokasi yang mendekati pelanggan. Topologi ini hanya membutuhkan satu atau sepasang serat optik yang menghubungkan $\mathrm{CO}$ dengan curb switch. Dari curb switch tersebut kemudian dihubungkan dengan serat optik menuju pelanggan. Pada Gambar. 4(b) terlihat bahwa panjang serat optik yang dibutuhkan masing-masing pelanggan hanya sepanjang jarak curb switch ke lokasi pelanggan, dengan penggunaan konektor fiber sebanyak $2 \mathrm{~N}$ ditambah dengan 2 konektor lagi untuk menghubungkan $\mathrm{CO}$ dan curb switch. Namun karena curb switch merupakan perangkat aktif, maka dibutuhkan sumber daya listrik untuk mengoperasikannya, sehingga masih diperlukan biaya operasional dan perawatan.

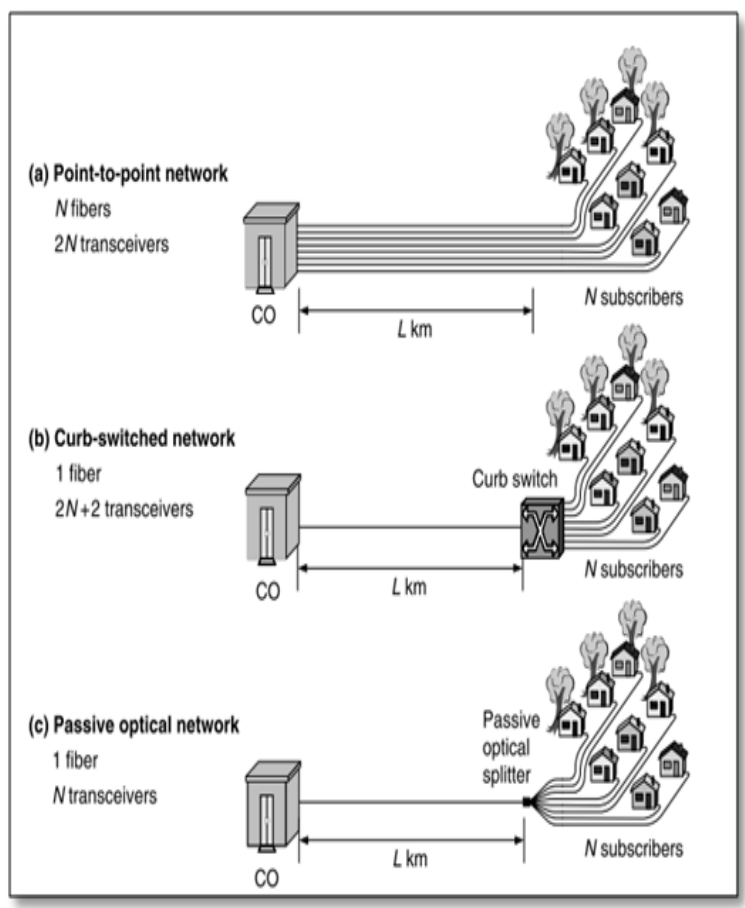

Gambar. 4 Fiber To The Home.

Passive Optical Network (PON) adalah solusi yang dapat menutupi kekurangan dua topologi di atas. Di dalam topologi PON, perangkat aktif yang berada di topologi curb - switched diganti dengan passive optical splitter yang harganya jauh lebih murah dibandingkan dengan harga perangkat curb switch, karena passive optical splitter merupakan perangkat yang pasif, tidak diperlukan daya listrik untuk memanfaatkannya. PON dapat mengurangi jumlah penggunaan serat optik, konektor fiber dan terminasi di sisi CO. Pada Gambar. 4 (c) dapat dilihat bahwa topologi PON hanya membutuhkan sejumlah $\mathrm{N}+1$ konektor dengan serat optik sepanjang $\mathrm{L} \mathrm{km}$. Jika pada Active Optical Network menggunakan dua serat optik untuk setiap sambungan, yaitu satu serat untuk mengirim sinyal atau Transmit ( $T x$ ) dan serat lain untuk menerima sinyal atau Receive $(R x)$, Passive Optical Network menggunakan satu serat optik untuk tiap pelanggan, dimana tidak lagi membedakan $T x / R x$ sinyal datanya, namun dibedakan melalui panjang gelombang cahayanya. Pembagian 
gelombang cahaya dilakukan oleh sebuah komponen bernama Wavelength Division Multiplexer (WDM). Transmisi data pada PON dilakukan menggunakan Optical Line Terminal (OLT) disisi CO dan Optical Network Unit / Terminal (ONU / ONT) yang berada disisi pelanggan (C. James Clifton, MS).

Pada tahun 2001, Institute of Electrical and Electronics Engineers (IEEE) membuat sebuah kelompok kerja bernama Ethernet in First Mile (EFM). Kelompok ini mengembangkan teknologi Ethernet yang sudah ada, salah satunya adalah menerapkan standard Ethernet untuk dapat berjalan diatas PON. Hasil kerja dari EFM salah satunya ada Ethernet PON (EPON). EPON merupakan jaringan PON - based Ethernet yang mentransmisikan data sesuai dengan standard Ethernet yaitu 802.3 di atas media transmisi PON dengan dengan lebar pita sebesar 1Gbps. Seiring dengan perkembangan lalu lintas data yang makin berkembang, pada tahun 2003 International Telecommunications Union-

Telecommunication Standardization Sector (ITU-T) membuat spesifikasi baru yaitu Gigabit-capable PON (GPON) yaitu ITU-T G.984.1 dengan lebar pita yang lebih besar.

"Recommendation ITU-T G.984.1 describes a flexible optical fibre access network capable of supporting the bandwidth requirements of business and residential services and covers systems with nominal line rates of $2.4 \mathrm{Gbit} / \mathrm{s}$ in the downstream direction and $1.2 \mathrm{Gbit} / \mathrm{s}$ and $2.4 \mathrm{Gbit} / \mathrm{s}$ in the upstream direction” (Itu-T, “G.984.1).

\subsection{Dual Homing}

"Dual - homing is a network topology that adds reliability by allowing a device to be connected to the network by way of two independent connection points",

(GarretCom Inc).

Dual Homing adalah sebuah topologi yang memungkinkan sebuah perangkat jaringan untuk terhubung ke perangkat jaringan lain melalui dua titik dan jalur yang berbeda. Dual Homing dibuat untuk meningkatkan reliabilitas jaringan. Sebuah jaringan mempunyai jalur utama (main) dan jalur cadangan (back up), tujuannya agar ketika sebuah jalur yang digunakan untuk mengirim dan menerima data mengalami gangguan misalnya terputus, maka perangkat tersebut masih mempunyai satu jalur back up, agar konektivitas perangkat jaringan tersebut menuju perangkat jaringan lain tetap dapat terselenggara. Gambar. 5 berikut mengilustrasikan wujud dual homing secara sederhana.

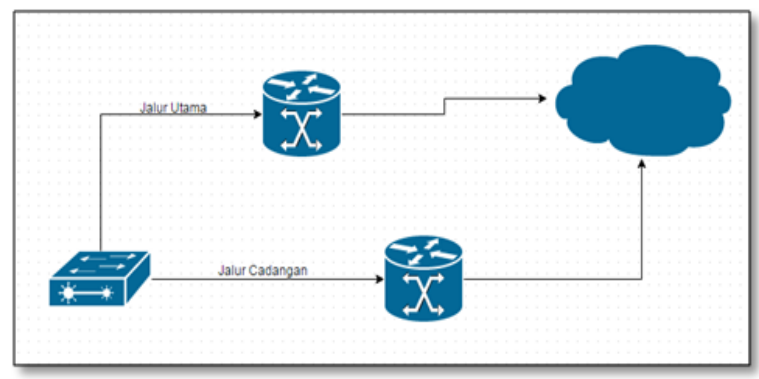

Gambar. 5 Dual Homing.

Dual Homing juga dapat diterapkan pada teknologi PON. Dual Homing PON menggunakan sebuah ONT yang mempunyai dua uplink. Uplink merupakan jalur yang digunakan sebuah perangkat jaringan untuk membentuk konektivitas dengan perangkat jaringan lain. Dalam hal ini, ONT yang memiliki dual uplink dapat terhubung ke satu atau dua OLT dengan jalur yang berbeda. Gambar. 6 di bawah ini menunjukkan sebuah ONT yang terhubung ke dua OLT berbeda melalui jalur yang berbeda. 


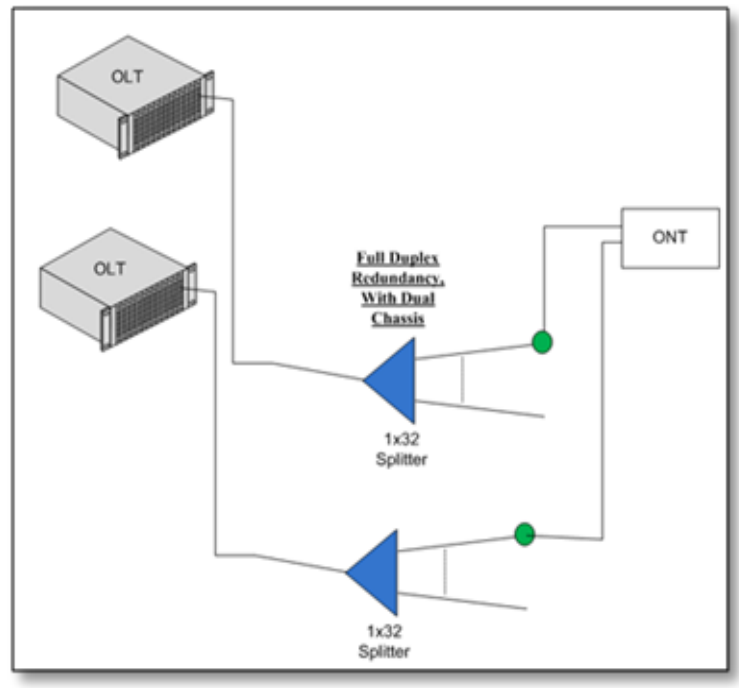

Gambar. 6 Dual Homing GPON.

(Optic Reach, 2012)

\section{METODOLOGI PENELITIAN}

\subsection{Topologi Sistem}

Sistem monitoring yang diaplikasikan saat ini adalah Cacti. Namun, karena metode monitoring Cacti hanya berbasis IP, maka jalur ONT Dual Homing tidak dapat dimonitor karena tidak hanya berbasis IP. Topologi ONT Dual Homing dapat dilihat pada Gambar. 7.

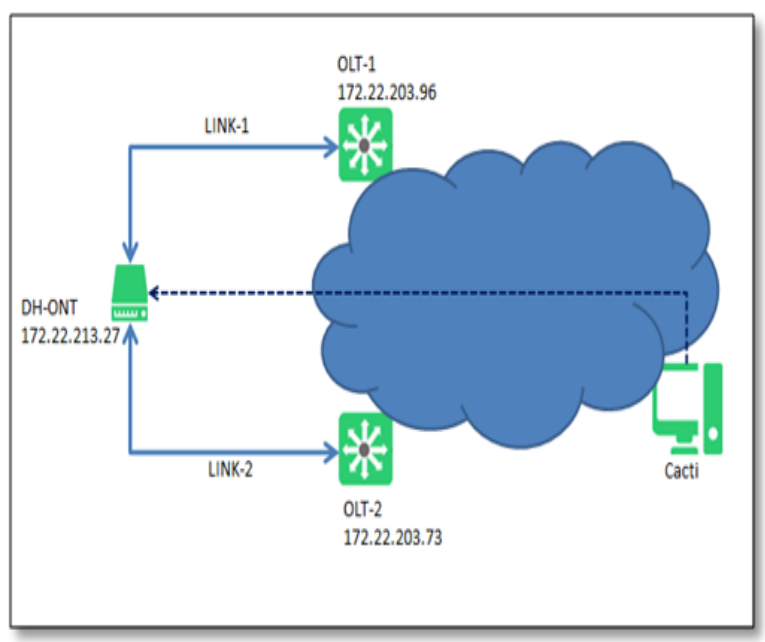

Gambar. 7 Skema Monitoring Dual Homing ONT.

Cacti memonitor ONT dengan alamat IP 172.22.203.27 yang akan menunjukkan indikator hijau apabila ONT dalam kondisi hidup. Gambar. 8 mengilustrasikan kondisi dimana sistem beroperasi dengan baik.

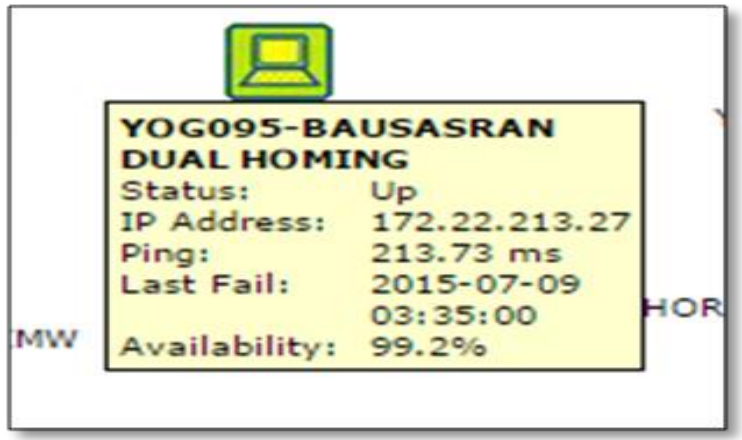

Gambar. 8 Indikator Hijau di Monitoring Cacti.

Gambar. 8 tersebut menunjukkan adanya informasi seperti Status, IP Address, Ping dan lainnya serta sebuah icon berwarna hijau jika kondisi perangkat dalam keadaan beroperasi normal. Gambar. 9 berikut mengilustrasikan suatu kondisi dimana salah satu jalur terputus. Jalur LINK-1 kondisinya terputus. Namun indikator di Cacti masih akan tetap menunjukkan warna hijau karena ONT masih dapat terkoneksi melalui jalur $L I N K$ - 2. Sebagai efek dari kondisi tersebut, kejadian putusnya jalur LINK - 1 tidak akan diketahui. Sedangkan memonitor IP OLT - 1 dan OLT - 2 saja tidak secara langsung merepresentasikan kondisi jalur yang digunakan ONT yang dimaksud, karena dalam sebuah OLT terdapat banyak ONT yang dilayani.

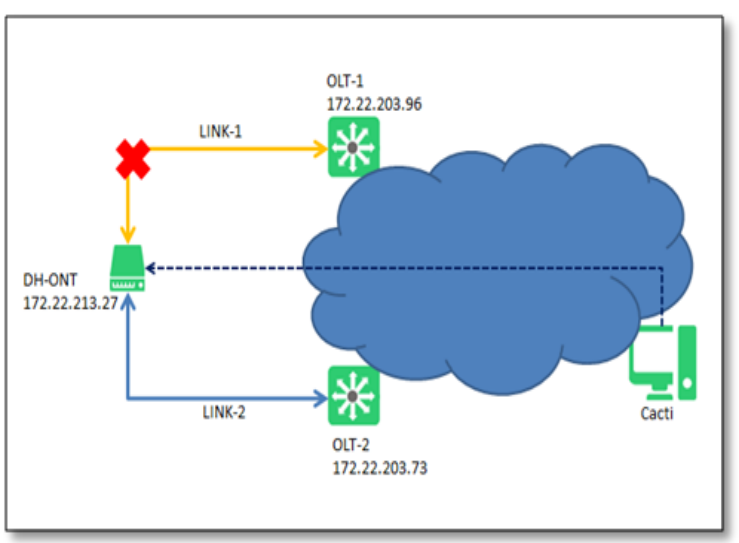

Gambar. 9 Skema Monitoring Dual Homing ONT dengan Jalur Putus.

\subsection{Perancangan Sistem}

Pada Gambar. 10, Cacti berjalan beiriringan dengan sistem baru yang berfungsi untuk monitoring ONT Dual Homing. Cacti memonitor ONT Dual 
Homing secara langsung dengan metode monitoring biasa, berdasarkan alamat IP dari ONT, sekaligus memonitor jalur yang mencatu ONT tersebut yaitu dengan memonitor logical port di mana ONT tersebut terdaftar di kedua sisi OLT. Monitor logical port ini dilakukan melalui NMS sebagai perantara bahasa proprietary NMS dengan perangkat OLT.

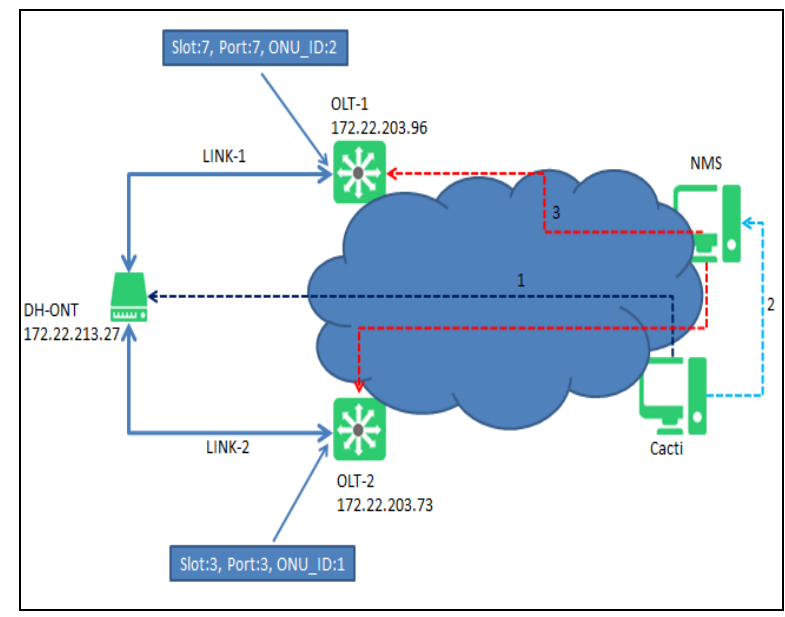

Gambar. 10 Topologi Sistem.

Urutan proses monitoring perangkat ONT dan link-nya sebagai berikut:

a. Cacti memonitor ONT langsung dengan memanfaatkan protokol SNMP. Proses ini akan menghasilkan informasi status dari ONT tersebut apakah dalam kondisi hidup atau mati.

b. Cacti melakukan koneksi TL1 sebagai antar muka yang disediakan oleh NMS dalam berinteraksi dengan sistem lain yang membutuhkan informasi dari NMS tersebut. Setelah koneksi terbentuk, Cacti mengirimkan perintah kepada NMS untuk mengetahui status dari logical port.

c. NMS mengirimkan perintah kepada OLT untuk mendapatkan informasi status logical port pertama yang diminta oleh Cacti. Setelah itu OLT merespon dan memberikan informasi kepada NMS. Kemudian secara paralel NMS meneruskan informasi yang diberikan OLT menuju Cacti.

Proses ke-2 dan ke-3 diulang dengan perintah yang berbeda untuk mendapatkan informasi logical port lain. Untuk dapat melakukan proses - proses tersebut, dibutuhkan rekayasa perangkat lunak di beberapa bagian Cacti, yaitu :

a. Modifikasi Form Input Device.

b. Modifikasi Table Host Database Cacti.

c. Modifikasi Script Penyimpanan Data.

d. Modifikasi Tampilan Plugin Monitor.

e. Penambahan Script Poller.

\subsection{Perancangan Perangkat Lunak}

Cacti memiliki keterbatasan dalam memonitor perangkat jaringan, yaitu hanya monitoring yang berdasarkan alamat IP. Oleh karena itu, maka perlu dilakukan modifikasi sehingga dapat memonitor logical port yang terdapat pada OLT agar dapat memonitor kondisi status ONT. Secara garis besar, modifikasi Cacti dilakukan pada beberapa komponen, yaitu: Tampilan Form Input Device, Tampilan Plugin Monitor serta beberapa modifikasi di dalam sistem.

\subsubsection{Modifikasi Form Input}

Cacti memiliki input seperti Gambar. 11. Form tersebut memiliki input Hostname yang dapat diisikan dengan alamat IP perangkat yang akan dimonitor. Penambahan input dilakukan agar form tersebut dapat menerima input lain untuk kebutuhan monitoring status ONT, yaitu Slot, Port dan Onu Id, serta tambahan input ONU Serial Number untuk menyimpan informasi Serial Number ONT yang dimonitor. Setelah dimodifikasi, form akan sesuai dengan Gambar. 12 yang berisi input tambahan, yaitu OLT Slot, OLT Port, ONU Id dan ONU Serial Number.

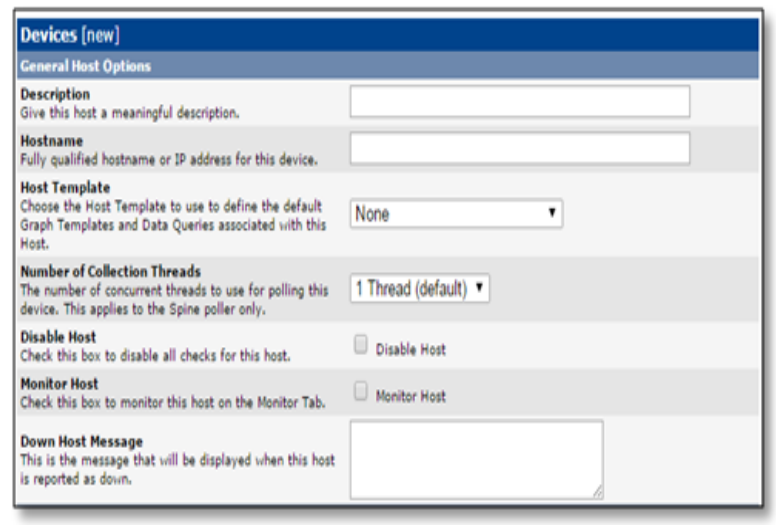

Gambar. 11 Form Input Device Cacti. 


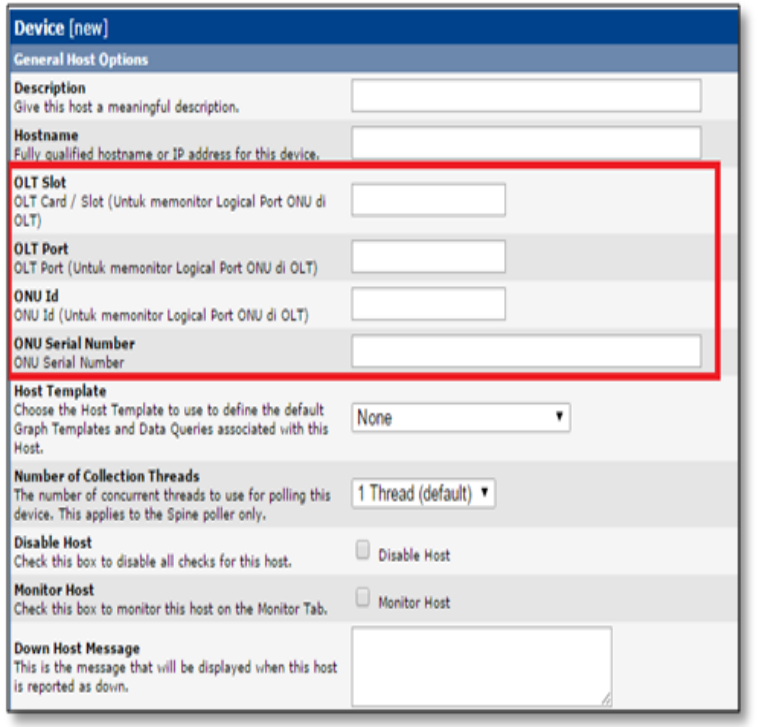

Gambar. 12 Form Input Device Cacti. (hasil modifikasi)

\subsubsection{Modifikasi Plugin Monitor}

Tampilan pada plugin monitor dimodifikasi agar lebih informatif. Tampilan monitor pada mode Tiles adalah seperti pada Gambar. 13. Agar lebih informatif untuk memonitor ONT Dual Homing, maka tambahan kolom baru di table juga ditampilkan di plugin monitor. Langkahnya adalah dengan mengubah script pada plugins / monitor / monitor.php agar dapat menampilkan slot dan port pada perangkat yang berfungsi sebagai link, maupun serial number pada ONT yang dimonitor.

\begin{tabular}{|c|c|c|}
\hline$\square$ & YK1_T $64 G$ & \\
\hline 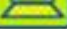 & Status: & $U_{p}$ \\
\hline & IP Address: & 172.22 .1 .30 \\
\hline & Ping: & $41.61 \mathrm{~ms}$ \\
\hline & Last Fail: & 2015-06-04 11:00:00 \\
\hline & Availability: & $99.4 \%$ \\
\hline
\end{tabular}

Gambar. 13 Tampilan Plugin Monitor di Cacti.

\section{HASIL PENELITIAN}

Sistem dibangun di lingkungan nyata dimana sistem ini terhubung ke network management ONT dan OLT. Namun karena ONT dan OLT berada para infrastruktur produksi, maka dilakukan simulasi dengan ONT dan OLT yang berada di lingkungan laboratorium seperti yang ditunjukkan oleh Gambar. 14. ONT yang dimaksud adalah yang ditandai dengan kotak berwarna biru, dan dua jalur ONT ditandai dengan kotak berwarna hijau di sebelah kanan. Terdapat pula dua buah patchcord berwarna kuning yang menandakan bahwa ONT tersebut memiliki dua jalur. Sistem diaplikasikan dengan topologi yang diilustrasikan pada Gambar. 15.

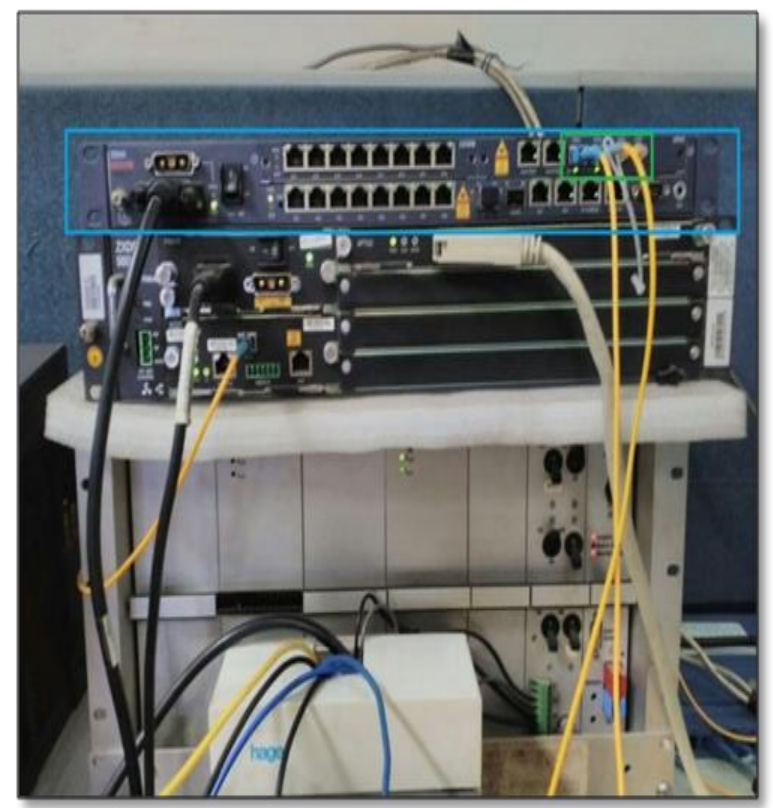

Gambar. 14 Foto ONT Dual Homing Lab.

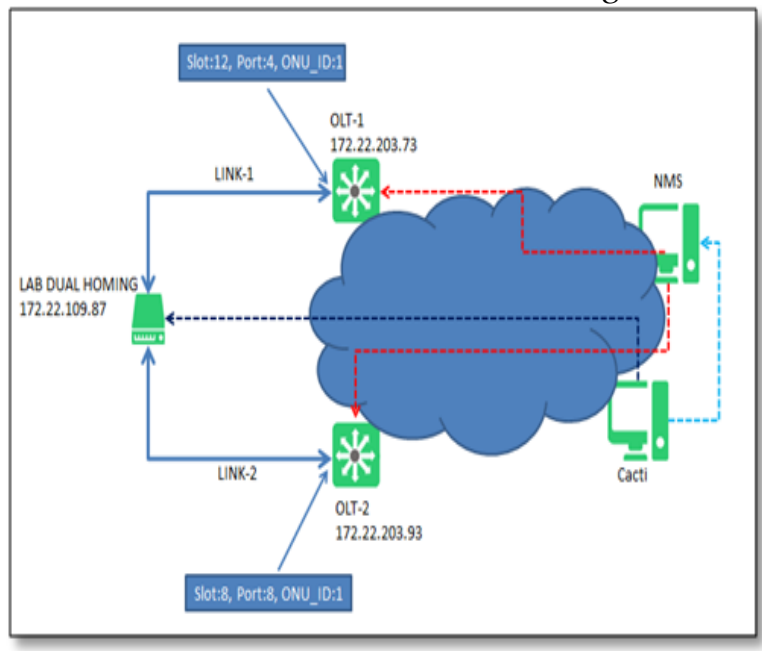

Gambar. 15 Topologi Simulasi Sistem.

Gambar. 15 menunjukkan bahwa Cacti memonitor ONT secara langsung, namun untuk memonitor jalur ONT, Cacti melewati NMS untuk pengambilan data yang dibutuhkannya, sehingga hasil monitoring dapat dilihat seperti pada Gambar. 16. 


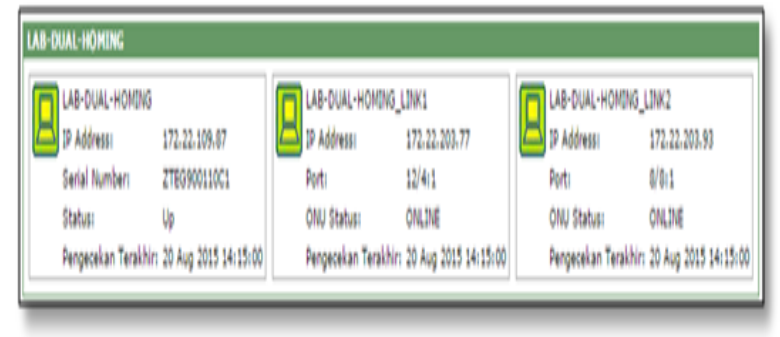

Gambar. 16 Tampilan Monitor Link Normal.

Proses selanjutnya adalah link failure test, dimana salah satu jalur akan dicabut. Gambar. 17 menunjukkan sistem yang terputus. Gambar tersebut menunjukkan bahwa LINK - 1 terputus (bertanda merah), namun ONT masih terkoneksi menggunakan LINK - 2 yang secara fisik terlihat seperti pada Gambar. 18. Hasil Link Failure Test dapat dilihat pada Gambar. 19 yang menunjukkan bahwa monitoring sistem berwarna merah.

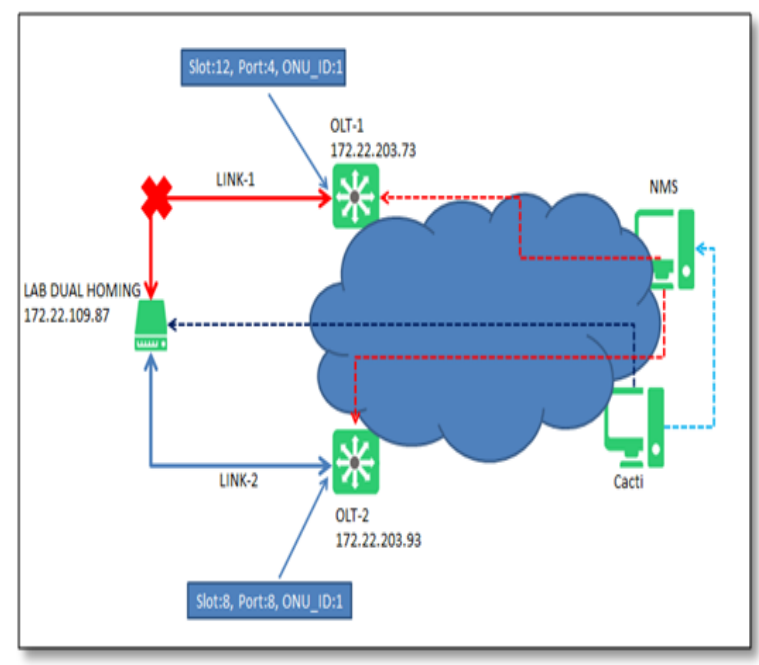

Gambar. 17 Topologi Simulasi Sistem dengan Link Down.

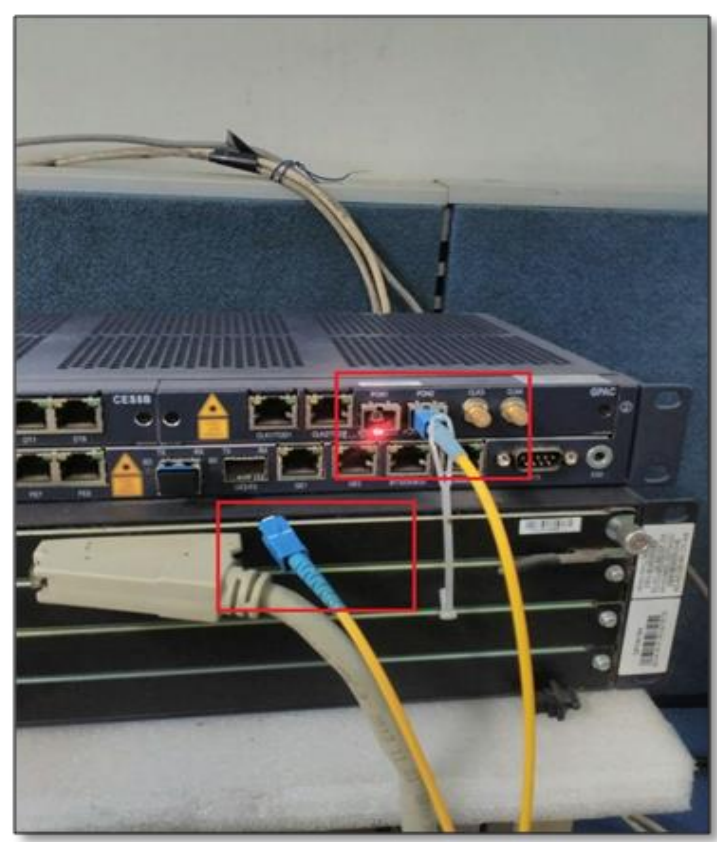

Gambar. 18 Salah Satu Jalur Dicabut.

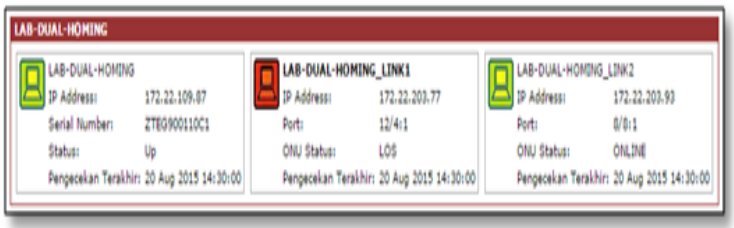

Gambar. 19 Tampilan Monitor Link Putus.

Pengujian selanjutnya adalah Device Failure Test, dimana sistem akan menjalani prosedur simulasi berupa pencabutan power perangkat untuk membuktikan apakah sistem monitoring dapat mendeteksi device failure.

Gambar. 20 menunjukkan bahwa sakelar power berada pada posisi mati, sehingga tidak ada power yang mengalir ke perangkat. Kondisi ini berhasil dideteksi oleh sistem dengan munculnya warna merah pada seluruh objek yang dimonitor, seperti ditunjukkan oleh Gambar. 21. 


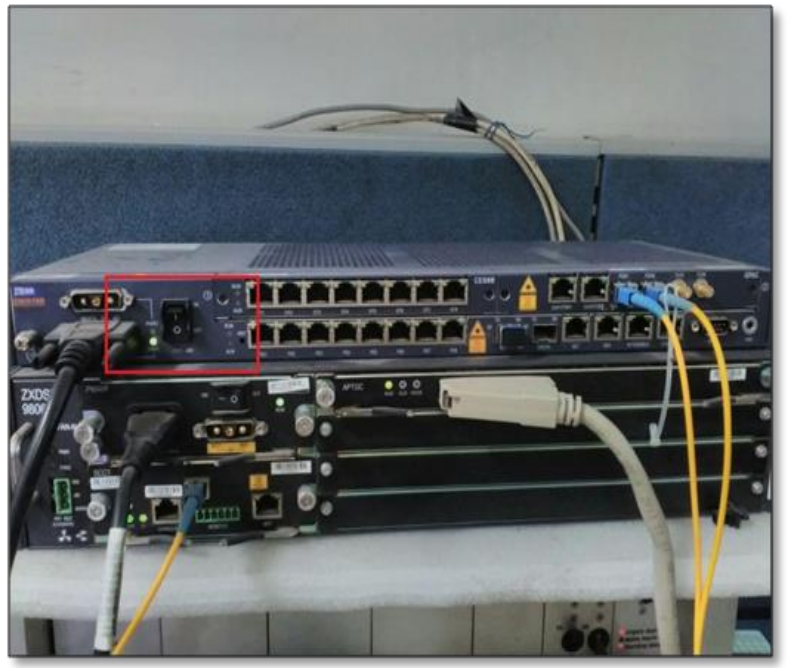

Gambar. 20 Simulasi ONT Dimatikan.

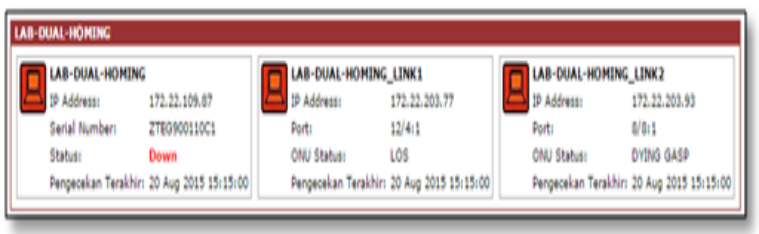

Gambar. 21 Tampilan Monitor dengan ONT $O F F$.

\section{KESIMPULAN}

Dari hasil simulasi yang dilakukan, sistem ini terbukti dapat menjawab permasalahan mengenai bagaimana memonitor jalur yang digunakan untuk ONT Dual Homing. Ketika sebuah ONT dengan dua jalur uplink dimonitor menggunakan sistem ini, kemudian disimulasikan salah satu jalur putus, sistem dapat mendeteksi jalur mana yang putus, kemudian menginformasikan kepada pengguna dalam bentuk tampilan monitor yang berwarna merah. Kemudian karena hanya salah satu jalur yang terputus, sistem dapat mendeteksi bahwa ONT nya itu sendiri masih hidup dengan jalur cadangan nya, dengan menggambarkan di tampilan monitor bahwa ONT dan jalur yang satunya masih dalam keadaan hijau.

Kemudian disimulasikan juga ketika ONT dimatikan daya listriknya, tampilan monitor ONT berubah menjadi merah, ditambah dengan tampilan monitor untuk jalur yang tadinya masih hijau menjadi merah juga. Karena secara logic di sisi OLT, ketika ONT tersebut dilakukan pengecekan, status nya memang dalam keadaan tidak hidup. Artinya sistem ini mampu mendeteksi baik secara fisik ONT-nya maupun secara logic di sisi OLT sebagai jalur yang dilewati ONT tersebut.

\section{DAFTAR PUSTAKA}

C. James Clifton, MS, "Green Network Solution - Passive Optical Network (PON)." GarretCom Inc., “. DualHoming: Bringing Redundancy to the Edge of the Network - A Technical Brief," no. 510, 2009.

Cacti Group, "Cacti ${ }^{\circledR}$ - The Complete RRDTool-based Graphing Solution." 2004.

Cisco, "Cisco ONS SONET TL1 for Beginners, Release 9.0.” 2013.

D. R. Mauro and K. J. Schmidt, Essential SNMP, vol. 1. 2005.

GSMA, "GSM.” 2015.

Itu-T, “G.984.1 Gigabit-capable passive optical networks (GPON): General characteristics," Networks, pp. 143, 2008.

J. A. De Vriendt, "Mobile Network Evolution.” 2002.

J. De Vriendt, P. Laine, C. Lerouge, and X. $\mathrm{X} . \mathrm{X} . \mathrm{Xu}, \quad$ Mobile network evolution: a revolution on the move," IEEE Commun. Mag., vol. 40, no. 4, 2002.

P. Murray, "SNMP: Simplified.” 2015.

W. Barth, Nagios: System and Network Monitoring. 2008. 